\title{
Geopolitical Issues in Human Computer Interaction
}

\author{
Jose Abdelnour Nocera ${ }^{1,2}$, Torkil Clemmensen ${ }^{3}$, Anirudha Joshi ${ }^{4}$, Zhengjie Liu ${ }^{5}$, Judy \\ van Biljon ${ }^{6}$, Xiangang Qin ${ }^{7}$, Isabela Gasparini ${ }^{8}$, and Leonardo Parra-Agudelo ${ }^{9}$ \\ ${ }^{1}$ University of West London, School of Computing and Engineering, London, UK \\ ${ }^{2}$ ITI/LARSyS, Funchal, Portugal \\ Jose.Abdelnour-Nocera@uwl.ac.uk \\ ${ }^{3}$ Copenhagen Business School, Frederiksberg, Denmark \\ tc.digi@cbs.dk \\ ${ }^{4}$ IIT Bombay, Industrial Design Centre, Mumbai, India \\ anirudha@iitb.ac.in \\ ${ }^{5}$ Sino-European Usability Center, Dalian Maritime University, China \\ liuzhj@dlmu.edu.cn \\ ${ }^{6}$ University of South Africa, School of Computing, Pretoria, South Africa \\ Vbiljja@unisa.ac.za \\ ${ }^{7}$ Beijing University of Posts \& Telecommunications, China \\ qinxiangang@aliyun.com \\ ${ }^{8}$ UDESC, Department of Computer Science, Joinville, SC, Brazil \\ isabela.gasparini@udesc.br \\ ${ }^{9}$ University of los Andes, Department of Design, Bogota, Colombia \\ leonardo.parra@uniandes.edu.co
}

\begin{abstract}
This workshop will explore and discuss geopolitical issues in Human Computer Interaction (HCI) as a field of knowledge and practice. These issues are mainly seen at two levels: (1) on discourses surrounding motivations and value of HCI as a sociotechnical field, and (2) on discourses surrounding concepts of $\mathrm{HCI}$ diffusion, maturity and diversity as articulated by global and local knowledge networks. Since the beginning of HCI, discussions of democracy have been around. It may even be fair to say that the key notion of usability aims to support the citizens of a democratic society. Obviously, exactly how HCI should do this remains open for discussion. HCI has several roots deep in military needs from the world wars of the 20th century. It was also born out of the sociotechnical traditions with its emancipatory ambitions, aiming at creating conditions for supporting human agency that facilitates the realization of people's needs and potential. There's an inherent contradiction between these traditions. Thus, we're interested in exploring the following question: how to reconcile such diverse discourses as military power and emancipatory ambitions in a geopolitical analysis of HCI research and associated discourses? Moreover, the diffusion of HCI as field of knowledge and practice is dominated by political and post-colonial discourses that pervade local and global knowledge networks shaping what is considered useful and relevant research and practice. In this workshop we understand these issues as geopolitical in nature and aim to trace the cultural and sociotechnical dynamics that construct the field of HCI.
\end{abstract}


Keywords: Geopolitical issues, Sociotechnical, HCI knowledge, HCI practice, Diffusion, Maturity, Diversity

\section{Introduction}

This workshop will explore and discuss geopolitical issues in Human Computer Interaction as a field of knowledge and practice. These issues are mainly seen at two levels:

(1) on discourses surrounding motivations and value of HCI as a sociotechnical field; (2) on discourses surrounding concepts of $\mathrm{HCI}$ diffusion, maturity and diversity as articulated by global and local knowledge networks.

Since the beginning of HCI, discussions of democracy have been around, e.g. [1,2]. It may even be fair to say that the key notion of usability aims to support the citizens of a democratic society or one that could be co-designed by its citizens. Originally, usability and the larger field of $\mathrm{HCI}$ was conceived for western democracies. Acknowledging that the meaning of emancipatory sociotechnical HCI depends on our ideas about the ideal society, models of democracy and participation becomes important. A review of studies of HCI and policy recapped basic models of democracy found in the literature [3]. Their models of democracy included a deliberative democracy, which is a system of governance that uses arguments in discussions until consensus is reached (Denmark may be an example); a Marxist system of governance that sees decision-making on policy as related to the economic system (China may be an example); and a cosmopolitan democracy [4] system of governance that highlights citizens', no matter their geographical location, rights to political participation in global affairs (UN may be an example). For HCI design approaches, the government system in its wider societal context is thus both a context for design and the ultimate end-goal of the design activities. $\mathrm{HCI}$ is both shaped by and may contribute to design of particular Marxist, deliberate, and cosmopolitan systems of governance. Policy makers and researchers may therefore benefit from knowing about and considering sociotechnical HCI approaches when they study and perform "democracy".

Obviously, exactly how HCI should shape and is shaped by these and other models of democracy and governance remains open for discussion. The influence of different models can be seen in the fact that HCI has several roots deep in military needs from the world wars of the 20th century [5], but it was also born out of the sociotechnical traditions with its emancipatory ambitions, that is, creating conditions for human workers, managers, etc. that facilitate the realization of their needs and potential $[4,5]$. In addition, the tension between the focus on the individual and on the social dimensions surrounding interaction is inherent in critical analyses of HCI, e.g.[6, 7]. How military power and emancipatory ambitions are related in a geopolitical analysis of HCI research? How do these ambitions influence or are influenced by globalization and economic development? How does the inherent tensions operate within the field? These are all tensions of geopolitical nature as they are underpinned by contrasting models of democracy and governance.

Moreover, the diffusion of $\mathrm{HCI}$ as field of knowledge and practice is dominated by political and post-colonial discourses that pervade local indigenous and global knowledge networks shaping what is considered useful and relevant research and 
practice $[8,9]$. The post-colonial analyses of $\mathrm{HCI}$ diffusion are fundamentally framed as set of intercultural and potentially uneven power relations in these 'design' situations of encounters [8]. However, there is also a need to focus on local and indigenous HCI concepts and methods [9] that are often invisible to professional and academic spaces of knowledge exchange [10]. The potential contribution of explicitly local or indigenous perspectives, approaches, and experiences with $\mathrm{HCI}$ tends to remain unknown, e.g. [11].

Last but not least, there are attempts to understand HCI maturity and diversity levels through origins, frequencies and levels of participation in conferences such as $\mathrm{CHI}$ or CSCW, e.g. [12]; through organizational adoption, e.g. [13, 14] or through regional institutionalizing efforts, e.g. [15]. The problem we identified is that HCI's maturity and diversity are placed on a continuum where western models of value, quality and participation reinforce political configurations of exclusion and inclusion, which regulate human and knowledge mobility in the field. Thus, limiting its potential to integrate other views, forms of being, living and understanding the world and the field itself.

\section{Workshop Objectives}

In this workshop we understand the above issues as geopolitical in nature and aim to trace the cultural and political dynamics that construct the field of HCI. More concretely, we will pursue the following objectives:

- To help develop a frame of understanding of geopolitical issues in HCI.

- To collect examples and experiences that show political discourses shaping HCl's motivations and values.

- To collect examples and experiences of HCI diffusion, maturity and diversity as articulated by global and local knowledge networks.

- To formulate a research agenda for future work on geopolitical research on HCI.

\section{$3 \quad$ Expected Outcomes}

The workshop will produce a research agenda for studying geopolitical issues through a HCI lens, and how best to understand and analyze them. The aim with this research agenda is to stimulate further research interest and provide direction for critical research on HCI. In addition, extended versions of the workshop papers will be published by Springer in the LNCS series as a volume collecting papers from the INTERACT2021 workshops.

\section{$4 \quad$ Target Audience}

The target audience for this workshop includes researchers and practitioners working on topics related to HCI diffusion, education, capacity building, and social studies of 
science and technology and critical research on HCI. Early-stage researchers and $\mathrm{PhD}$ students are also encouraged to submit work-in-progress papers.

\section{$5 \quad$ Organizing Committee}

The workshop is organized by IFIP TC13 WG13.8 - Interaction Design for International Development. The organizers are:

José Abdelnour Nocera is professor in Sociotechnical Design and Head of the Sociotechnical Centre for Innovation and User Experience at the University of West London. He is the current Chair for IFIP TC13 WG13.8 and the British Computer Society Sociotechnical Specialist Group. His interests lie in the sociotechnical and cultural aspects of systems design, development and use.

Torkil Clemmensen is professor at the Department of Digitalization, Copenhagen Business School, Denmark. His research interest is in psychology as a science of design. His research focuses on cultural and psychological perspectives on usability, user experience, and the digitalization of work. He contributes to Human-Computer Interaction, Design, and Information Systems. He is a vice-chair of IFIP TC13 WG8.

Anirudha Joshi is professor in the interaction design stream in the IDC School of Design. He works in the area that can be described as "Interaction Design for Indian Needs", which aims to solve some age-old problems by leveraging new technologies. Anirudha has worked in diverse domains including healthcare, literacy, Indian language text input, banking, education, and accessibility.

Zhengjie Liu, Professor at Dalian Maritime University, China, has been working in HCI since 1989. He founded the Sino European Usability Center in 2000 as the first research center dedicated to usability in China. He is a co-founder of SIGCHI China and CCF TC-HCI. He is awardee of ACM SIGCHI Lifetime Achievement in Service Award (2017) and IFIP TC13 Pioneers Award (2013).

Judy van Biljon holds the National Research Foundation's Chair in Information and Communication for Development (ICT4D) hosted by the School of Computing at the University of South Africa (Unisa). She has contributed to the body of academic knowledge by publishing on Human-Computer Interaction evaluation and interaction design for marginalised groups, technology adoption, and sustainability in digital learning for resource-constrained environments. She serves as Associate Editor of Information Technology for Development and as a Senior Editor of the Electronic Journal of Information Systems in Developing Countries.

Xiangang Qin is currently a lecturer in the School of Digital Media and Design Arts at Beijing University of Posts \&Telecommunications. Prior to current job, Xiangang Qin used to work in the Department of Digitization at Copenhagen Busi-ness School as postdoctoral and international incoming fellowship, Lenovo, China Mobile and Siemens. His research interests include issues of UX in context-aware systems, UX measurement and culturability issue of HCI.

Isabela Gasparini received her Ph.D. degree from the Federal University of Rio Grande do Sul (UFRGS - Brazil) with a sandwich period at TELECOM Sud Paris (France). She is currently an Associate Professor at the Santa Catarina State University 
(UDESC), where she is involved in Human-Computer Interaction and Technology-Enhanced Learning fields, with a special interest in adaptive e-learning systems, gamification, learning analytics, recommender systems, infoviz, and cultural issues. She is the editor-in-chief of the Brazilian Journal of Computers in Education (2019-2021), and the coordinator of the Special Human-Computer Interaction committee of the Brazilian Computer Society.

Leonardo Parra-Agudelo is a part of the team that constitutes the school of Architecture and Design at Universidad de los Andes (Bogota, Colombia). Leonardo finished a $\mathrm{PhD}$ in urban matters and social transformation at QUT, holds an MFA in design and technology from Parsons the New School for Design, studied design in Colombia, and is also a certified motorbike technician and everything-two-wheel rider. He believes in in-disciplinary and disobedient research and creative practice, and explores how to blur disciplinary boundaries, through care-full interactions.

\section{References}

1. Bjørn-Andersen, N., Clemmensen, T.: The Shaping of the Scandinavian Socio-technical IS Research Tradition. Scandinavian Journal of Information Systems. 29, 79-118 (2017).

2. Bødker, S., Ehn, P., Sjögren, D., Sundblad, Y.: Co-operative Design—perspectives on 20 years with 'the Scandinavian IT Design Model.' In: proceedings of NordiCHI. pp. 22-24 (2000).

3. Nelimarkka, M.: A Review of Research on Participation in Democratic Decision-Making Presented at SIGCHI Conferences. Toward an Improved Trading Zone Between Political Science and HCI. Proceedings of the ACM on Human-Computer Interaction. 3, 1-29 (2019).

4. Archibugi, D., Koenig-Archibugi, M., Marchetti, R.: Introduction: Mapping global democracy. (2011).

5. Shackel, B.: Human-computer interaction-Whence and whither? Journal of the American society for information science. 48, 970-986 (1997).

6. Dillon, A.: Group Dynamics Meet Cognition: applying socio-technical concepts in the design of information systems. In: The New SocioTech: Graffiti on the Long Wall. pp. 119-125. Springer Verlag, London (2000).

7. Abdelnour-Nocera, J., Clemmensen, T.: Theorizing About Socio-Technical Approaches to HCI. In: IFIP Working Conference on Human Work Interaction Design. pp. 242-262. Springer, Cham (2019).

8. Irani, L., Vertesi, J., Dourish, P., Philip, K., Grinter, R.E.: Postcolonial Computing: A Lens on Design and Development. In: Proceedings of the SIGCHI Conference on Human Factors in Computing Systems. pp. 1311-1320. ACM, New York, NY, USA (2010). https://doi.org/10.1145/1753326.1753522.

9. Abdelnour-Nocera, J., Clemmensen, T., Kurosu, M.: Reframing HCI Through Local and Indigenous Perspectives. International Journal of Human-Computer Interaction. 29, 201-204 (2013). https://doi.org/10.1080/10447318.2013.765759.

10. Suchman, L.: Located Accountabilities in Technology Production. Scand. J. Inf. Syst. 14, 91105 (2002). 
11. Kurosu, M., Kobayashi, T., Yoshitake, R., Takahashi, H., Urokohara, H., Sato, D.: Trends in usability research and activities in Japan. International Journal of Human-Computer Interaction. 17, 103-124 (2004).

12. Sturm, C., Oh, A., Linxen, S., Abdelnour Nocera, J., Dray, S., Reinecke, K.: How WEIRD is $\mathrm{HCI}$ ? Extending HCI Principles to Other Countries and Cultures. In: Proceedings of the 33rd Annual ACM Conference Extended Abstracts on Human Factors in Computing Systems. pp. 2425-2428. Association for Computing Machinery, New York, NY, USA (2015). https://doi.org/10.1145/2702613.2702656.

13. Guidini Gonçalves, T., Marçal de Oliveira, K., Kolski, C.: HCI in practice: An empirical study with software process capability maturity model consultants in Brazil. Journal of Software: Evolution and Process. 30, e2109 (2018).

14. Lacerda, T.C., Wangenheim, C.G. von: Systematic literature review of usability capability/maturity models. Computer Standards \& Interfaces. 55, 95-105 (2018). https://doi.org/10.1016/j.csi.2017.06.001.

15. Smith, A., Joshi, A., Liu, Z., Bannon, L., Gulliksen, J., Li, C.: Institutionalizing HCI in Asia. In: Baranauskas, C., Palanque, P., Abascal, J., and Barbosa, S.D.J. (eds.) Human-Computer Interaction - INTERACT 2007. pp. 85-99. Springer Berlin Heidelberg, Berlin, Heidelberg (2007). 